\title{
Thi, 㐫 LEGISLACIÓN COLOMBIANA RELACIONADA CON LOS ECOSISTEMAS DE MANGLAR
}

\author{
Colombian legislation related to mangrove ecosystems
}

Ricardo Álvarez-León ${ }^{1}$, José Ricardo Álvarez-Puerto²

\begin{abstract}
RESUMEN
Con el fin de rescatar los avances en el conocimiento adquirido sobre los ecosistemas de manglar del Caribe y Pacífico de Colombia, se realizó una revisión de las normas directa e indirectamente relacionadas. A partir de dicha revisión se obtuvo una cantidad apreciable de información que se presenta y analiza en el presente artículo. Esta información confirma que estos humedales costeros poseen un considerable potencial que hasta ahora no ha sido aprovechado en forma adecuada y que las condiciones ecológicas de las especies involucradas, permite tener la certeza de que la correcta administración, conservación y uso sustentable, asegurara una recuperación bastante promisoria.
\end{abstract}

Palabras clave: caracterización, legislación, manglares, Caribe, Pacífico, Colombia.

\begin{abstract}
To highlight the advances in knowledge gained on mangrove ecosystems in the Caribbean and Pacific Colombia, there was a revision of standards related directly and indirectly. From this review we obtained a significant amount of information presented and discussed in this article. This information confirms that these coastal wetlands have considerable potential that has not yet been tapped properly and that the ecological conditions of the species involved, can be assured that proper management, conservation and sustainable use, to ensure enough recovery promising.
\end{abstract}

Keywords: characterization, legislation, mangrove, Caribbean, Pacific, Colombia.

\footnotetext{
${ }^{1}$ Fundación Verdes Horizontes. Manizales (Caldas) Colombia, ricardoalvarezleon@gmail.com

2 Universidad de Manizales. Facultad de Derecho. Manizales (Caldas) Colombia. joseralvarezp@yahoo.com
} 


\section{INTRODUCCION}

En Colombia, de la variedad de tipos de bosques (500.000 km² aprox.) las áreas más importantes para el sector forestal son las regiones de Urabá, la cuenca del río San Juan y las del sur del Pacífico (entre Buenaventura y Tumaco) que representa algo más del $15 \%$ de la superficie boscosa (Neyra-Román, 1981; Gaviria-Flórez y GonzálezPalacio, 1998). Pero las Reservas Forestales se han visto disminuidas en forma acelerada por el intenso aprovechamiento forestal, la explotación minera y la colonización espontánea e intensa. Por esta razón y con el propósito de encarar los problemas de regeneración de los bosques naturales y establecer los servicios de apoyo a futuras reforestaciones se planteó el Proyecto INDERENA/PNUD/FAO-COL / 74 / 005 en 1975. La investigación incluyó ensayos y experimentos de campo, desarrollo de métodos y sistemas silviculturales propios de los bosques húmedos tropicales tanto del Caribe como del Pacífico. No obstante, aunque se tuvieron en cuenta las asociaciones predominantes: (1) bosques de manglar, (2) bosque de guandal, (3) bosque de colinas bajas, (4) bosque de colinas altas, para el Pacífico, y (5) bosque de catival y (6) bosques mixtos o de colinas en el Caribe, al final primó el hecho de contar con áreas propias para hacer seguimiento de regeneración natural, recurriendo a la colaboración de las empresas privadas relacionadas con actividades de aprovechamiento forestal, y sólo se realizaron los trabajos de plantación de 18 especies, técnicas de vivero con 20 especies y regeneración natural en bosques de guandal (complejo de asociaciones vegetales de bosque pantanoso del Pacífico colombiano) donde se reconocen varios ecosistemas: (1) sajal (Campnosperma panamensis), (2) cuangariales (Otoba gracilipes), (3) naidizales (Euterpe oleracea), (4) guandales mixtos (Ceiba pentadra, Terminalia amazonica, Castilla elastica, Vochisia sp.), y cativales (Prioria copaifera), en cuanto a las asociaciones que directa o indirectamente tienen relación con el manglar (Neyra-Román, 1981; Del Valle-Arango, 1996).

A pesar de los valiosos aportes de la silvicultura colombiana en más de 300 especies tanto nativas como exóticas y la enorme producción documental de la última década (Silva, 1987), la existencia de trabajos sobre los esfuerzos en la silvicultura de los manglares en el país, era bastante escasa y en algunos aspectos inexistente, pero con la realización del Proyecto MMA / OIMT entre 1995-2003, se dieron las bases para un desarrollo sustentable de dicha actividad en las costa colombianas. (GuevaraMancera, 1998; Guevara-Mancera et al., 1998; Rodríguez-Cruz, 1998; Sánchez-Páez \& UlloaDelgado. 2000; Sánchez-Páez et al., 2000; SánchezPáez et al., 1997a, 1997b; Sánchez-Páez et al., 2000; Ulloa-Delgado et al., 1998a, 1998b; ZambranoEscamilla \& Rubiano-Rubiano. 1996, 1997).

La vulnerabilidad de los ecosistemas de manglar conformados por ocho especies (Avicennia germinans, Conocarpus erecta, Laguncularia racemosa, Pelliciera rhizophorae y Rhizophora mangle, en el Caribe y A. germinans, C. erecta, L. racemosa, Mora oleifera, $P$. rhizophorae, $R$. harrisoni, $R$. mangle y $R$. racemosa, en el Pacífico), y la constante presión a la que han sido sometidos por la acción antropogénica, han generado diversos ensayos para su recuperación en las costas colombianas. (Álvarez-León, 1997, 2006)

Los manglares en el país, desde mediados de este siglo han sido objeto de aprovechamiento forestal, para obtener los productos requeridos en la construcción de la vivienda popular, como son varas, vigones, horcones y pilotes, al igual que para postes de redes eléctricas y madera para leña y carbón; casi todas las embarcaciones artesanales en la zona costera, (canoas, cayucos, potrillos), son de mangle o tienen parte de él.

En la costa sobre el Mar Caribe se han efectuado aprovechamientos del bosque, por ejemplo, extrayendo astillas de madera para la construcción de tableros aglomerados, labor esta que se suspendió en 1978 y en las costas del Océano Pacífico entre 1945 y 1975 se realizó el aprovechamiento de la corteza de los árboles para la extracción de tanino, para lo cual se apeaban los árboles y se dejaba la madera en el bosque.

A continuación se ofrece una reseña breve sobre los alcances, logros y retos de la legislación que se generó en el Proyecto Manglares en Colombia, MMA/ ACOFORE/OIMT, entre Septiembre de 1995 y Abril de 2002, en sus diferentes en sus períodos: Fase I, Fase II-Etapa 1 y Fase II-Etapa 2.

\section{Alcances del Proyecto}

- Fortalecer la generación de alternativas productivas social y ambientalmente adecuadas para el uso sustentable del manglar, garantizando la conservación y la preservación de los mismos para que los pobladores de los litorales colombianos sean los primeros beneficiarios.

- Elaborar un diagnóstico detallado sobre el estado de los ecosistemas de manglar en los litorales y territorios insulares del Caribe y 
Pacífico colombianos para su adecuado aprovechamiento y conservación e identificar unidades de manejo.

- Avanzar en la realización de estudios de carácter general en el Caribe y el Pacífico sobre la estructura, función y dinámica de los ecosistemas de manglar y sobre los procesos económicos y sociales prioritarios.

- Procurar acciones para poner en funcionamiento los mecanismos y conductos legales, institucionales, de participación y financiación que garanticen tanto la realización como la continuidad de acciones del proyecto para la consecución del objetivo de desarrollo del mismo.

- Lograr un incremento significativo en el conocimiento sobre la regeneración natural, crecimiento y fenología de los manglares, así como de limitantes y potencialidades de los manglares del Caribe y del Pacífico de Colombia y determinar opciones para orientar los procesos económicos y sociales hacia el desarrollo sustentable de los mismos.

- Desarrollo de proyectos productivos piloto y de manejo integrado de manglares, en las dos costas de Colombia, mediante procesos de concertación con organizaciones de carácter público y con las comunidades locales y procurar el fortalecimiento de las comunidades locales en función del buen manejo de los manglares.

- Procurar la participación de las organizaciones públicas encargadas de la administración de los recursos naturales y de los manglares y en especial obtener el concurso y la participación de representantes de las comunidades locales en todas las acciones del trabajo de campo. Adicionalmente se adoptó también como estrategia el suministrar en forma constante y oportuna la información sobre el Proyecto y los resultados que se estaban obteniendo, manteniendo esquemas flexibles para efectuar cambios en el evento de que ello se requiriese.

\section{Retos del Proyecto}

- A través de análisis rápido de campo efectuado en 1991, por el Instituto Nacional de Recursos Naturales Renovables y del Ambiente INDERENA, al igual que por medio de otros estudios se determinó que los ecosistemas de manglares en el país se encontraban bastante afectados en su composición, estructura, densidad y algunos de ellos se encontraban bastante deteriorados por diversas causas y factores entre los que se hallaban el aprovechamiento inadecuado del componente vegetal, construcción de obras civiles, algunos desarrollos urbanos, turísticos e industriales y acciones diversas y que causan deterioro a los estuarios.

- $\mathrm{Al}$ respecto no se contaba con estudios y documentos a nivel de todo el país, que con certeza señalaran, para los diversos ecosistemas de manglares existentes en las dos costas, las causas específicas de su deterioro, así como la real zonación, composición, estructura y densidad y en general se desconocía un estado actualizado de todos los sectores de manglares y de sus constituyentes en cada caso.

- Si bien es cierto que se tenía información sobre el uso general que se daba a los manglares, se desconocían los diferentes usos, bienes y servicios de los mismos por sectores, tipos de productos extraídos, comunidades dedicadas al aprovechamiento de los manglares, relaciones de éstas con los ecosistemas, necesidades de los moradores de los manglares, sentires y pareceres, sentido de pertenencia, tradiciones étnicas y culturales.

- La legislación existente con respecto a manglares no era muy específica y los datos con que se contaba respecto a la estructura administrativa para el manejo de los manglares indicaban muy poca gestión y muy escasos programas dirigidos a orientar el manejo sostenible de los mismos.

- No se tenía una serie de mapas adecuada con la localización verdadera de los manglares del país y a escala conveniente para diversos trabajos, con excepción de algunos de ellos. En resumen no se poseían informaciones de detalle respecto a la caracterización de los manglares del país para poder guiar el manejo y la conservación hacia la sustentabilidad.

- Antes de comenzar la Fase II (Etapa I) del Proyecto Manglares de Colombia, sólo se contaba en el país con un número muy reducido de parcelas para el análisis del crecimiento en diámetro de los árboles de mangle, así como para los estudios de regeneración natural y la fenología, establecidas por este Proyecto en su primera fase. 
- El hábitat de muchos manglares en el país se ha venido deteriorando, en especial por excesiva salinidad, falta de oxígeno y altas temperaturas, además de la muerte de los árboles en algunas áreas y además del aprovechamiento no sostenible en otras, sin que existieran estaciones de monitoreo y control que permitiesen conocer oportunamente los cambios en los datos de los diferentes parámetros y adoptar las acciones pertinentes.

- Con anterioridad al inicio del Proyecto Manglares de Colombia sólo en dos lugares del país se tenía alguna experiencia de la actividad de producción de plantas de mangle en vivero y la posterior siembra, pero sin ninguna clase de seguimiento a estas actividades, requiriéndose el establecimiento de varios viveros y del establecimiento de parcelas para experimentación de las actividades de restauración, con el registro permanente de su comportamiento.

- No se tenían experiencias del desarrollo de proyectos de producción piloto con las comunidades locales, ni de programas de fortalecimiento de las organizaciones comunitarias en acciones compatibles con el manejo sostenible de los manglares y sus recursos asociados.

\section{Logros del Proyecto}

\section{Fase I}

Documentación y Mapas. Se recopilaron y analizaron una serie de artículos, libros, textos y documentos de información secundaria (inéditos y publicados) sobre los manglares de Colombia, se montó una base de datos modelo CDS - ISIS.

Estructura y Composición. Con los datos se efectúo análisis utilizando el IVI. Se establecieron también parcelas permanentes de crecimiento, según la composición del bosque. A las cuales se han venido tomando mediciones para registrar crecimiento en diámetro, regeneración natural y fenología.

Parcelas Permanentes de Crecimiento. En el Caribe se establecieron 25 de las cuales 10 ya fueron objeto de la segunda medición. En general los árboles con menores diámetros promedios manifestaron los más altos incrementos anuales en diámetro. En el Pacífico se establecieron 27, de las cuales 9 de ellas de la segunda medición y en general, $R$. mangle, fue la más abundante, con árboles de $23,5 \mathrm{~cm}$ promedio de diámetro, y con incremento anual $0,31 \mathrm{~cm}$.
Regeneración Natural. En el Caribe, la Guajira registró valores muy bajos: 0,28 /0,35 propág./ $\mathrm{m}^{2}$, correspondiendo a $L$. racemosa la más registrada; en el Magdalena valores bajos de 2,66 propág./ $\mathrm{m}^{2}$ hasta valores muy bajos de 0,39 propág./ $\mathrm{m}^{2}$; en Bolívar, valores altos de 39,41 propág. $/ \mathrm{m}^{2}$ promedio, medios entre 5,16 y 4,73 y bajos 0,87 propág. $/ \mathrm{m}^{2}$, siendo $R$. mangle, la más abundante, seguida por L. racemosa y A. germinans. En Córdoba los mayores registros con 88,16 propágulos $/ \mathrm{m}^{2} /$ mes, y una fructificación muy abundante de L. racemosa. En el Pacífico: Se estructuraron 27 sub-parcelas de $4 \mathrm{~m}^{2}$ para escasos 7 meses de registros en áreas de Nariño, se determinó que las diferencias significativas en la disponibilidad de propágulos de Rhizophora spp., estuvieron directamente relacionadas con la fructificación estacional de la especie; la implantación y el reclutamiento de plántulas parecen estar más relacionadas con la presencia de árboles maduros y en general la especie presentó un descenso notorio en la implantación de propágulos, que coincide con el período de lluvias más intenso en la región.

Publicaciones. Se elaboraron 2 libros, 1 cartilla y 1 sonoviso, con el Diagnóstico y la Zonificación para el Manejo Sustentable de los manglares del Pacífico y Caribe de Colombia. Incluyen información de campo, procesada y analizada posteriormente, sobre los aspectos físicos, bióticos, ecológicos, estado actual, impactos y aspectos socioeconómicos delos manglares. La zonificación contempla Zonas para la Preservación, Uso Múltiple, Recuperación y Producción, así como lineamientos para el manejo de cada una de ellas. Así mismo, se elaboraron e imprimieron mapas en escala 1:100.000, con sus respectivas memorias para cada uno de los Departamentos.

\section{Fase I Etapa 1}

Documentación y Mapas. Se produjeron mapas a escala 1: 100.000 sobre los tipos de manglares en la costa Pacífica, con la situación a 1969, 1996 y la integración multi-temporal, utilizando las imágenes del Radar INTERA y mapas a la misma escala de los manglares del Caribe colombiano, utilizando imágenes del Satélite LANDSAT, para la zonificación preliminar y manejo sustentable.

Parcelas Permanentes de Crecimiento. En el Caribe, se continuó el registro de datos para análisis de la dinámica. Además, se llevaron a cabo una serie de Proyectos Productivos Comunitarios, en el Urabá Antioqueño, Córdoba, Sucre, Bolívar, y Magdalena. 
Evaluación de Calidad Fisicoquímica. Determinación de la calidad de las aguas en las zonas adyacentes a los manglares del Caribe y del Pacífico, en Guajira, Magdalena, Bolívar, Sucre, Córdoba, Antioquia, Choco, Valle, Cauca y Nariño.

Publicaciones. Se elaboraron 2 libros, sobre la conservación y uso sostenible de los manglares del Caribe y del Pacífico colombiano, la recuperación de los manglares de los manglares del Pacífico y Caribe de Colombia y 1 libro sobre los aspectos sociales y antropológicos de los población de mangleros del Pacífico de Colombia. Así como 35 Informes Técnicos sobre documentación, manejo de fauna y flora, dinámica, establecimiento de Parcelas Permanentes de Crecimiento, registro de crecimiento en diámetro, regeneración natural, y fenología (épocas de fructificación, floración y caída de hojas) al igual que se registraron datos sobre los parámetros fisicoquímicos de las aguas, mercadeo.

\section{Fase I Etapa 2}

Parcelas Permanentes de Crecimiento. En el Caribe, se continúa con el registro de datos en Parcelas Permanentes de Crecimiento para análisis de la dinámica.

Proyectos Productivos Comunitarios. Se llevaron a cabo una serie de Proyectos en el Urabá Antioqueño, Córdoba, Sucre, Bolívar, y Magdalena.

Evaluación de Calidad Fisicoquímica. Con la colaboración de las comunidades, se restablecieron los flujos hídricos de zonas hipersalinas de manglar en el Caribe.

Recuperación de Áreas Degradadas. Se restauraron 100 ha. de manglares en la costa Caribe, mediante trabajo colaborativo de las comunidades.

Seguimiento. Se continuaron las labores de Producción de Plántulas de Mangle en Viveros, los Talleres para la Concertación de Lineamientos Estratégicos Preliminares sobre administración, manejo, conservación y control de ecosistemas de manglares. Tomando como base las necesidades de manejo sostenible de los manglares y como mecanismos de fortalecimiento de las organizaciones locales se coadyuvó al logro de la capacitación de estas comunidades en aspectos de Educación Ambiental, Rescate de los Conocimientos Tradicionales de Aprovechamiento de los Manglares, a través de Encuentros de Saberes sobre los manglares y sobre el diseño e implementación gradual de un Plan de Acción Socialconfundamento en el fortalecimiento de las organizaciones en áreas de manglar.

Publicaciones. Se elaboraron 2 libros sobre los lineamientos estratégicos para la conservación y uso sostenible de los manglares de Colombia, 1 película, 5 manuales para el manejo de viveros, parcelas de crecimiento y, 2 artículos sobre restauración y zonificación de los manglares del Pacífico y del Caribe de Colombia.

\section{Análisis de las Normas Jurídicas}

\section{Normas Relacionadas a Nivel Nacional}

Decreto - Ley 2811 de diciembre 18 de 1974. Por el cual se dicta el Código Nacional de Recursos Naturales Renovables y de Protección al medio Ambiente.

Artículos 164, 165, 166 y 327.

Decreto 2324 del 18 de septiembre de 1974. Por medio del cual se reorganiza la Dirección General Marítima y Portuaria.

Artículo 1, 2, 19, 166, 167 y 178.

Ley 0013 del 15 de enero de 1990. Por el cual se dicta el Estatuto General de Pesca.

Artículos 1, 2 y 7. Una vez definidos, la administración y manejo integral de tales recursos pesqueros será de competencia exclusiva de la Autoridad Pesquera Nacional (INDERENA, INPA, INCODER, ICA y actualmente la AUNAP).

Ley 0001 de enero 10 de 1991. Por la cual se expide el Estatuto de Puertos Marítimos y se dictan otras disposiciones.

Ley 0021 de marzo 4 de 1991. Por medio del cual se aprueba el convenio 169 sobre pueblos indígenas y tribales en el Países independientes, adoptado por la $76^{a}$ reunión de la conferencia general de la OIT, Ginebra 1989.

Artículo 7 Numeral 4; 15 Numerales 1 y 2.

Ley 0070 de 27 de agosto de 1993. Por la cual se desarrolla el artículo transitorio 55 de la Constitución Política de 1991.

Artículo 1, 2, 4 y 6.

Ley 0099 de 23 de diciembre de 1993. Por la cual se crea el Ministerio del Medio Ambiente, se reordena el Sector Público encargado de la gestión y conservación del medio ambiente y los recursos naturales renovables, se organiza el Sistema Nacional Ambiental, SINA, y se dictan otras disposiciones. 
Artículo 5, 65, 66, 67, 76 y 108.

Ley 0160 de 3 agosto de 1994. Por la cual se crea el Sistema Nacional de Reforma Agraria y Desarrollo Rural Campesino, se establece un subsidio para la adquisición de tierra, se reforma el Instituto colombiano de la Reforma Agraria y se dictan otras disposiciones.

Artículo 12.

Resolución 1602 del 21 de diciembre de 1995, del Ministerio del Medio Ambiente. Por medio de la cual se dictan medidas para garantizar la sostenibilidad de los manglares en Colombia.

Artículo 1. Definiciones: Para los efectos de la presente resolución se adoptan las siguientes definiciones:

Manglar: Entiéndase como Manglares los ecosistemas de zonas costeras en los que se relacionan especies arbóreas de diferentes familias denominadas mangle con otras plantas, con animales que allí habitan permanentemente o durante algunas fases de su vida, y con las aguas, los suelos y otros componentes del ambiente.

Fuente de Impacto Directo: Cualquier obra, industria, o actividad que se localice dentro del área de Manglar, y que destruya su cobertura forestal o altere los procesos ecológicos del ecosistema.

Fuente de impacto indirecto: Cualquier obra, industria o actividad que se localice fuera del área de Manglar, y que cause la destrucción de su cobertura forestal o altere los procesos ecológicos del sistema.

Aprovechamiento Forestal: Sustracción de productos forestales.

Aprovechamiento Forestal Único: El que se realice con el fin de destinar suelos a usos diferentes del forestal, o el que no sea persistente.

Aprovechamiento Forestal Persistente: El que se efectúa con la obligación de conservar el rendimiento normal forestal con técnicas silvícolas que permitan la renovación del recurso.

Zonificación: Subdivisión de un territorio con fines de manejo ambiental.

Plan de Manejo Forestal: Es el plan que de manera detallada, establece las condiciones que se requieren para prevenir, mitigar, controlar, compensar y corregir los posibles efectos o impactos ambientales negativos causados en el desarrollo de una actividad de aprovechamiento forestal; incluye planes de seguimiento, evaluación, monitoreo y contingencia, que permitan el aprovechamiento forestal persistente.

Restauración: Es la recuperación y adecuación morfológica y ecológica de un área afectada por actividades que hayan introducido modificaciones al paisaje o causado impacto a los recursos naturales.

Artículo 2. Prohibiciones. Se prohíben las siguientes obras, industrias y actividades que afectan el manglar.
A. Aprovechamiento forestal único de los Manglares.

B. Fuentes de impacto directo e indirecto.

Parágrafo: Se exceptúan las labores comunitarias de acuicultura artesanal que no causen detrimento al manglar y que sean debidamente aprobadas por las entidades administrativas de los recursos naturales competentes.

Artículo 3. Aprovechamiento Forestal Persistente. (inciso 1) Permítase el aprovechamiento forestal persistente del Manglar en áreas forestales productoras, una vez el Ministerio del Medio Ambiente apruebe las propuestas de zonificación y las actividades a las que se refiere el artículo $4^{\circ}$, o apruebe planes de manejo forestal ya existentes de las autoridades ambientales regionales o los interesados en el aprovechamiento forestal del Manglar, previa expedición de los permisos correspondientes, y sujeto a las condiciones impuestas por los planes de ordenamiento y manejo forestal.

Artículo 4. El Ministerio del Medio Ambiente remitirá los términos de referencia a las autoridades ambientales regionales en cuya jurisdicción se encuentren áreas de manglar para que éstas realicen y presenten al Ministerio, en un término de 18 meses contados a partir de la recepción de los términos de referencia, estudios sobre el estado de los manglares en el territorio de su competencia y sobre el estado de los manglares en el territorio de su competencia y sobre las actividades tradicionales comunitarias de aprovechamiento forestal, dándose prioridad a éste último. Las autoridades procederán a elaborar propuestas para la zonificación y realización de actividades, para lo cual el Ministerio entregará unos términos de referencia y aportará los resultados de los estudios que haya adelantado sobre el manglar, así como la información secundaria disponible. El Ministerio del Medio Ambiente apoyará a las autoridades ambientales regionales en la asignación de recursos, para que éstas cumplan con los estudios y las propuestas en mención. El Ministerio del Medio 
Ambiente estudiará los resultados de los estudios anteriormente mencionados, y las propuestas de zonificación y de actividades, y procederá a dar los alineamientos y las directrices para el manejo de las diferentes áreas de Manglar.

Artículo 5. Control y vigilancia. Las autoridades competentes deberán realizar un monitoreo permanente de los depósitos y expendios de Mangle, con el fin de evitar la comercialización ilegal del mangle.

Artículo 6. Seguimiento y evaluación. El Ministerio del Medio Ambiente, a través de las entidades científicas adscritas y vinculadas a éste, particularmente el Instituto de Investigaciones Marinas y Costeras, "José Benito Vives D’Andreis" INVEMAR, prestará el apoyo técnico a las autoridades ambientales regionales en cuya jurisdicción se encuentren áreas de Manglar para diseñar y desarrollar los programas de seguimiento y evolución de las actividades relacionadas con estos ecosistemas, con el fin de verificar el cumplimiento de las condiciones fijadas en la expedición de permisos para su aprovechamiento.

Resolución 0020 del 9 de enero de 1996, del Ministerio del Medio Ambiente. Por medio de la cual se aclara la Resolución 1602 de diciembre de 1995, y se dictan otras disposiciones.

Una errada interpretación surgió de las disposiciones de la Resolución 1602 de 1995, cuando se entendió que se buscaba prohibir todo tipo de actividades en las zonas de Manglar, idea que resulta claramente contradictoria con el concepto de Desarrollo Humano Sostenible, objetivo principal del Ministerio del Medio Ambiente.

Por lo tanto con el fin de lograr una debida aplicación y eficacia de las disposiciones anteriores, se aclaran el artículo segundo, el tercero y el cuarto.

Artículo 1. Al Artículo 2 de la Resolución 1602 de 1995 se le agregan dos parágrafos.

1. El aprovechamiento forestal único será permitido sólo cuando tenga por objeto la construcción de obras de interés público siempre y cuando existan planes de compensación y restauración a que haya lugar.

2. La prohibiciones del numeral dos del Artículo 2 segundo operarán en el momento en que conlleven al deterioro del ecosistema de Manglar a juicio de la autoridad competente.
Artículo 2. El artículo tercero quedará así: Permítase el aprovechamiento forestal persistente del Manglar en áreas forestales productoras; una vez el Ministerio del Medio Ambiente apruebe la zonificación de las áreas de Manglar, elaborada por las Corporaciones Autónomas Regionales, a las cuales hace referencia el artículo cuarto de esta resolución.

Se le agrega un parágrafo transitorio 2, que dispone: Hasta tanto se aprueben los planes de zonificación a los cuales hace referencia el artículo cuarto de esta resolución, los particulares que pretendan adelantar aprovechamiento forestal persistente, podrán solicitar el permiso ante la Corporación Autónoma Regional competente, previa presentación de un plan de manejo forestal, el cual deberá contar con un concepto previo del Ministerio del Medio Ambiente.

Artículo. 3. Las vedas que establezcan las corporaciones autónomas tendrán plena vigencia.

Artículo. 4. En todo lo demás continúa vigente en la Resolución 1602 de 1995.

Ley 0357 de 21 de enero de 1997. Por la cual se aprueba la convención relativa a los humedales de importancia internacional, especialmente como hábitat para las aves acuáticas, suscrita en Ramsar (Irán), el 2 de febrero de 1991.

Artículo 1, 2, 3 y 4.

Resolución 0257 del 26 de marzo de 1997, del Ministerio del Medio Ambiente. Por medio de la cual se establecen controles mínimos para contribuir a garantizar las condiciones básicas de sostenibilidad de los ecosistemas de manglar y sus zonas circunvecinas.

Artículo 1. Establecer un sistema de monitoreo y control de la calidad de las aguas, flora, fauna y suelos de los ecosistemas de manglar presentes en las ciénagas, estuarios, deltas y lagunas de las zonas costeras de los litorales colombianos.

Dentro de las consideraciones se dijo que: En la Ciénaga Grande de Santa Marta durante el periodo comprendido entre 1975 y 1990, se murieron 26.000 hectáreas de Manglares por la hiper-salinización de las aguas y los suelos, debido a la sedimentación y taponamiento de los caños de agua dulce provenientes del río Magdalena, que la dotaban de salinidad adecuada y del indispensable flujo laminar.

Y que además la ruptura del balance hidrológico de los sistemas por interrupción de los flujos de agua dulce de los ríos a ciénagas y de agua 
salada del mar hacia los estuarios y deltas, provocan cambios en la salinidad de los suelos y de las aguas con graves perjuicios para los ecosistemas.

Artículo 3. Como parte de los elementos indicadores esenciales del buen estado de los ecosistemas de manglares y sus zonas circunvecinas, se efectuarán observaciones y registros periódicos permanentes de sus componentes bióticos, que permitan analizar su diversidad y abundancia, se seleccionarán organismos indicadores de procesos de acumulación de algunas sustancias de interés sanitario, según el Decreto 1594 de 1984.

Artículo 4. Las Corporaciones Autónomas Regionales y las Corporaciones para el desarrollo sostenible, recopilarán y analizarán la información cartográfica disponible, así como las fotografías aéreas y las imágenes de satélite, de manera rutinaria y comparativa, con el fin de detectar los grandes cambios geomorfológicos que causan grandes daños ambientales a los estuarios $\mathrm{y}$, por ende, a los manglares debido al proceso de sedimentación.

Artículo 7. El registro de la información que se obtenga de los monitoreos se deberá enviar al Ministerio del Medio Ambiente y al INVEMAR, y este último conformará una base de datos que compartirá con el IDEAM, manejará la información y efectuará permanentemente la divulgación sobre el estado de las diferentes áreas y las necesidades de acción.

Artículo 9. Las Corporaciones Autónomas Regionales y las Corporaciones para el Desarrollo Sostenible, propenderán por un permanente contacto e intercambio de información con los usuarios y habitantes de las áreas de Manglares y sus alrededores, para tener conocimiento oportuno de las situaciones de orden económico y social que se presenten en éstos ecosistemas, así como sobre cambios drásticos o graduales que afecten los patrones económicos específicos, con fines según sea el caso y competencias. Igualmente, las Corporaciones Autónomas Regionales y las Corporaciones para el Desarrollo Sostenible celebraran un Foro Anual sobre Manglares por convocatoria del Ministerio del Medio Ambiente y del INVEMAR en la Ciénaga Grande de Santa Marta, para analizar la información recopilada y observar los procesos de restauración ambiental de Manglares que allí se adelantan.

Resolución 0924 del 16 de octubre de 1997, del Ministerio del Medio Ambiente. Por medio de la cual se establecen términos de referencia para estudios sobre el estado actual y propuestas de zonificación de las áreas de manglar en Colombia.

En virtud de la Resolución 1602 de 1995 y de las disposiciones de ésta en el Artículo 4:

Artículo 1. En este artículo se precisa lo ya dicho en el Art. 4 de la Resolución 1602. Aquí se incluyen los términos de referencia de los estudios. Se señalan las actividades específicas que deberán ser efectuadas por las CAR y de desarrollo sostenible en cuya jurisdicción se encuentren áreas de manglar.

Artículo 2. Son incluidos tres anexos que servirán como guía para tener en cuenta en el desarrollo de los términos de referencia fijados en la resolución:

1. Manual metodológico para estudios forestales.

2. Manual metodológico para estudios sociales y económicos.

3. Manual metodológico de algunos elementos de ayuda para la redacción del diagnóstico, y la Determinación de Unidades de Manejo y la Planificación Estratégica.

Resolución 0233 del 29 de marzo de 1999, del Ministerio de Medio Ambiente. Por medio de la cual se modifica la Resolución 0924 del 16 de octubre de 1997 y se prorroga el plazo previsto en el artículo $4^{\circ}$ de la Resolución 1602 del 21 de diciembre de 1995.

Artículo 2. Modifica el numeral 2 del art1 de la Resolución 0924 del 16 de diciembre de 1997: -se deberá complementar la información elaborada por el Proyecto Manglares de Colombia, respecto del diagnóstico y zonificación preliminar de los Manglares del Caribe y del Pacífico de Colombia.

Artículo 3. Prorrogar por un año el término señalado en el Art.4o de la Resolución 1602 de 1995, contado a partir de su vencimiento, es decir, el próximo mes del abril de 1999.

Ley 1377 del 8 de enero 2010. Por medio de la cual reglamenta la actividad de reforestación comercial.

Artículo 3. Atribuciones del Ministerio de Agricultura y Desarrollo Rural. El Ministerio de Agricultura y Desarrollo Rural, como organismo rector de la producción agropecuaria, forestal y pesquera, es la única entidad competente para formular las políticas del sector forestal comercial y sistemas agroforestales, así como el otorgamiento y reglamentación del Certificado de Incentivo Forestal, CIF, para apoyo de programas de reforestación comercial. 
Artículo 7. Protección de bosques naturales y ecosistemas estratégicos. No podrán establecerse cultivos forestales o sistemas agroforestales con fines comerciales en bosques naturales, áreas forestales protectoras, áreas de manejo especial o cualquier otra categoría de manejo, conservación o protección que excluya dicha actividad, así como ecosistemas estratégicos, tales como Páramos, Manglares, Humedales.

\section{Normas Específicas a Nivel Regional}

\section{- Costas del Mar Caribe}

Ley 0062 del 7 de septiembre de 1937. Por la cual se ordenan obras en Cartagena.

Es la primera norma sobre limpieza y canalización de los caños, y terraplenado y urbanización de sus orillas. Esta ley así como las otras Leyes, Decretos, Resoluciones, Acuerdos y Ordenanzas sobre los cuerpos de agua de Cartagena, están relacionadas con los manglares, uno de los humedales más importantes y abundantes sobre los cuales se estableció y se ha desarrollado el $90 \%$ de la ciudad.

Ley 0015 del 19 de abril de 1961. Por la cual se provee a la construcción del alcantarillado de Cartagena.

El Artículo 1 señala que para dar cumplimiento a las Leyes 0010 de 1941 y 0008 de 1944, así como a las obligaciones que la Nación ha contraído por pactos internacionales para sanear los puertos de primera categoría, la Nación asume todos los gastos que demande la construcción del alcantarillado sanitario y pluvial que se construye actualmente en Cartagena.

Resolución 0191 del 31 de agosto de 1964, del Ministerio de Agricultura. Por la cual se reservan y declaran como Parques Nacionales Naturales, tres sectores de tierras baldías en el Departamento del Magdalena.

Artículo 1. Con el fin de preservar la flora, la fauna y las bellezas escénicas naturales, resérvense y declárense Parques Nacionales Naturales, los siguientes sectores de tierras presumiblemente baldías:

1. Un área de 21.000 hectáreas de extensión aproximada, que se denominará Parque Nacional Natural de la "Isla de Salamanca".

2. Un sector de 12.000 hectáreas de extensión aproximada, que se denominará Parque Nacional Natural de Santa Marta

3. Una zona de 114.000 hectáreas de extensión aproximada que comprende las partes altas de las hoyas hidrográficas de los Ríos Mendiguaca, Guachaca, Buritaca y Don Diego, la vertiente izquierda del Río Palomino y la vertiente derecha del Río Piedras. Esta zona que se denominará en adelante Parque Nacional Natural Tayrona.

Resolución 0292 del 18 de agosto de 1969. Por la cual se aprueba el Acuerdo 004 de 24 de abril de 1969, originario de la Junta Directiva del Instituto de Desarrollo de los Recursos Naturales Renovables INDERENA.

Acuerdo 0004 de 24 de abril de 1969. Por el cual se delimitan y reservan dos áreas de tierras ubicadas en el Departamento del Magdalena. Artículo 1.

Acuerdo 0025 del 2 de mayo de 1977. Por el cual se modifican los límites del Parque Nacional Natural Sierra Nevada de Santa Marta, en los Departamentos de Magdalena, Guajira y Cesar.

Artículo 1. Con el objeto de conservar la flora, la fauna, las bellezas escénicas naturales, complejos geomorfológicos, manifestaciones históricas o culturales, con fines científicos, educativos, recreativos o estéticos, ampliase el área del Parque Nacional Natural Sierra Nevada de Santa Marta hasta trescientas ochenta y tres mil (383.000) hectáreas de superficie aproximada, distribuidas dentro de las jurisdicciones municipales de Santa Marta, Ciénaga, Aracataca y Fundación (Departamento del Magdalena), Riohacha (Departamento de la Guajira), San Juan del Cesar y Valledupar (Departamento del Cesar).

Acuerdo 0026 del 2 de mayo de 1977. Por el cual se reserva, alinda y declara como Parque Nacional Natural un área ubicada en el Departamento de Bolívar.

Artículo 1. Con el objeto de conservar la flora, la fauna, las bellezas escénicas naturales, complejos geomorfológicos, manifestaciones históricas o culturales, con fines científicos, educativos, recreativos o estéticos, delimitase y reservase un área de diecisiete mil ochocientas (17.800) hectáreas de superficie aproximada que se denominará Parque Nacional Natural Los Corales del Rosario, ubicado dentro de la jurisdicción del Municipio de Cartagena, Departamento de Bolívar.

Acuerdo 0029 del 2 de mayo de 1977. Por el cual se reserva, alinda y declara como Santuario de Flora y de Fauna un área ubicada en el Departamento del Magdalena.

El Departamento del Magdalena posee una gran extensión de manglares en el Santuario.

Artículo 1. Con el objeto de preservar especies vegetales y animales, con fines científicos y educa- 
tivos y para conservar recursos genéticos de la Flora y Fauna Nacional, delimitase y resérvese un área de veintitrés mil (23.000) hectáreas que se denominará Santuario de Flora y Fauna de la Ciénaga Grande de Santa Marta ubicada dentro de las jurisdicciones municipales de Pivijay y Remolino en el Departamento del Magdalena.

Resolución 0172 del 24 de mayo de 1977, del Ministerio de Agricultura. Por la cual se aprueba el Acuerdo 0034 del 24 de mayo de 1977, originario de la Junta Directiva del Instituto Nacional de los Recursos Naturales Renovables y del Medio Ambiente INDERENA.

Artículo 1. Con el objeto de conservar la flora, la fauna y las bellezas escénicas naturales, con fines científicos, educativos, recreativos o estéticos, delimítense y resérvense las siguientes zonas:

1. Un área con veintiún mil (21.000) hectáreas de superficie aproximada, que se denominará parque nacional natural de la isla de salamanca, ubicado dentro delas jurisdicciones municipales de Sitio Nuevo y Pueblo Viejo, en el Departamento del Magdalena.

2. Una zona de quince mil (15.000) hectáreas de superficie aproximada, que se denominará Parque Nacional Natural Tayrona, ubicada en la jurisdicción del Municipio de Santa Marta, en el Departamento del Magdalena

Acuerdo 0034 del 24 de mayo de 1977. Por el cual se declara un área como Zona de protección, propagación y estudio de Flamencos ubicada en el Departamento de la Guajira. Artículo 1.

Artículo 1. Declarar como Zona de Protección, Propagación y Estudio de Flamencos o Chiclocos, (Phoenicopterus ruber) la región comprendida por la concesión de Salinas Marítimas de Manaure dentro de la jurisdicción municipal de Manaure y el área utilizada para anidar en la Bahía Portete en el Municipio de Uribia, Departamento de La Guajira.

Resolución 0164 del 6 de junio de 1977. Por la cual se aprueba el Acuerdo 0025 del 2 de mayo de 1977, originario de la Junta Directiva del Instituto Nacional de los Recursos Naturales Renovables y del Ambiente INDERENA.

Resolución 0165 del 8 de junio de 1977. Por la cual se aprueba el Acuerdo 0026 del 2 de mayo de 1977, originario de la Junta Directiva del Instituto Nacional de los Recursos Naturales Renovables y del Ambiente INDERENA.

Resolución 0168 del 8 de junio de 1977, del Ministerio de Agricultura. Por la cual se aprueba el Acuerdo 0029 del 2 de mayo de 1977, originario de la
Junta Directiva del Instituto Nacional de los Recursos Naturales Renovables y del Ambiente INDERENA.

Resolución 0169 del 6 de junio de 1977. Por medio de la cual se aprobó el Acuerdo 0030 del 2 de mayo de 1977 de julio de 1985, de la Junta Directiva del INDERENA, que creó el Santuario de Flora y Fauna de los Flamencos, en jurisdicción del Municipio de Riohacha.

En este Santuario se encuentran zonas con ecosistemas de manglar.

Decreto 1741 del 4 de agosto de 1978, del Ministerio de Agricultura. Por medio del cual se reglamentan parcialmente la Ley 0023 de 1973, el DecretoLey 2811 de 1974 y los Decretos 2349 de 1971 y 0133 de 1976, en lo relacionado con la creación de un Área de Manejo Especial.

Por esta norma el Ministerio de Obras y Transporte tendrá la responsabilidad de las obras de dragado y mantenimiento de la Ciénaga de la Virgen, la cual posee Manglares en sus alrededores.

Ley 0007 del 4 de enero de 1984. Por medio de la cual se ordena la ejecución de la recuperación sanitaria de los caños, lagunas y ciénagas de Cartagena.

Acuerdo 0038 del 9 de julio de 1985. Por el cual se aclaran los linderos del Parque Nacional Natural de la Isla de Salamanca.

Artículo 1. Aclarar el artículo 1 numeral primero del Acuerdo No. 004 de abril 24 de 1969, el cual quedar de la siguiente forma: (1) Un área con veintiún mil (21.000) hectáreas de superficie aproximada que se denominará Parque Nacional Natural Isla de Salamanca, ubicada dentro de las jurisdicciones municipales de Sitio Nuevo y Pueblo Viejo, en el Departamento del Magdalena.

Resolución 0283 del 7 de octubre de 1985. Por la cual se aprueba el Acuerdo 0038 del 9 de julio de 1985, originario de la Junta Directiva del Instituto Nacional de los Recursos Naturales Renovables y del Ambiente INDERENA.

Acuerdo 0058 del 20 de noviembre de 1991, del Consejo de Cartagena. Por el cual se aprueba el Plan de Desarrollo Ambiental y Sanitario de la ciudad de Cartagena al año 2010.

Se dictan normas relacionadas con el saneamiento ambiental y sanitario, el programa de acueducto y de aseo urbano de la ciudad. Como se sabe en estas obras intervendrían los ecosistemas de manglar aún supervivientes en la ciudad y sus cuerpos de aguas adyacentes. 
Acuerdo 0099 del 2 de agosto de 1992, de la Corporación para el Desarrollo Sostenible de Urabá, CORPOURABÁ. Por el cual se declara la Ensenada de Rionegro, Reserva Natural.

En el Artículo 1. se especifica que la reserva natural incluye toda la ensenada y sus alrededores, que posee manglares, incluyendo los bajos o chapales, helechales y arracachales húmedos al Sur de Rionegro (Departamento de Antioquia).

Resolución 0292 del 11 de diciembre de 1992, del INDERENA. Mediante la cual se otorga licencia ambiental al Proyecto Integral de Transporte Masivo y Saneamiento del Distrito Cultural y Turístico de Cartagena de Indias.

Norma complementaria de la Ley 0062 de 1937, sobre la limpieza y canalización de los caños, y terraplenado y urbanización de sus orillas, generalmente cubiertas de manglares y otra vegetación asociada.

Ley 0047 del 19 de febrero de 1993. Por la cual se dictan normas especiales para la organización y el funcionamiento del Departamento Archipiélago de San Andrés, Providencia y Santa Catalina.

Artículo 4, 23, 24, 25, 26, 34, 35 y 38.

Ordenanza 0012 del 29 de junio de 1993, del Concejo de San Andrés Isla. Por medio de la cual se crea la Zona Especial de Reserva de Manglar comprendida entre Bahía Hooker y Bahía Honda, localizadas en San Andrés Isla.

En el Art. 3 ratifica que se trata de una reserva de manglar, y en el Art. 26 se destina la zona de manglar baldía, con referencia catastral 01-37-00-053-000.

Acuerdo 0052 del 14 de septiembre de 1993, del Consejo de Cartagena. Por el cual se dictan normas relacionadas con la reglamentación del uso del suelo en la Isla de Barú y la Zona Norte de Cartagena.

El Artículo 3, incluye aspectos del Plan de Manejo Ecológico y Ambiental, y el Plan Vial de la Isla de Barú.

Acuerdo 0014 del 25 de marzo de 1994, del Concejo de Cartagena. Por el cual se adopta el Plan Maestro de Ordenamiento Físico para la isla de Barú y la Zona Norte de Cartagena, y se definen los parámetros para la elaboración de los Planes de Desarrollo e Inversiones para los sectores que conforman dichas zonas.

El articulado incluye diferentes aspectos relacionados con las áreas de manglar. Art.10 clasificación de las áreas de manejo; Art. 75 manglares y áreas inundables; Art.135 áreas de protección ambiental; Art. 231 sectorización de las áreas de protección ambiental.

Ley 0136 del 2 de junio de 1994 Por la cual se dictan normas tendientes a modernizar la organización y el funcionamiento de los municipios.

Artículo 12. Declara como Parque Nacional los manglares del Archipiélago de San Andrés, Providencia y Santa Catalina.

Resolución 76395 B del 4 de agosto de 1995, de la Corporación para el Desarrollo Sostenible de Urabá, CORPOURABÁ. Por medio de la cual se fijan los montos de las tasa para el aprovechamiento de los bosques públicos y privados.

El Artículo 3, prohíbe el aprovechamiento de trece especies maderables- incluido el mangle rojo, Rhizophora spp., cuyo aprovechamiento bajo cualquier modalidad queda completamente vedado.

Resolución 1021 del 13 de septiembre de 1995, del Ministerio del Medio Ambiente. Por la cual se reserva y declara el Parque Nacional Natural Old Providence and Mc Bean Lagoon, en el Municipio de Providencia.

Artículo 1. (Modificado por la [Resolución 0013 de 1996, artículo 1]). Reservase y declarase Parque Nacional Natural Old Providence \& Mc Bean Lagoon, la zona que se encuentra comprendida por los siguientes limites (...)

Parágrafo. Dentro del área alindada en el artículo anterior quedan prohibidas las actividades diferentes a las de conservación, educación, recreación, cultura, recuperación, control; en especial la adjudicación de baldíos y las contempladas en los (Artículos 30 y 31 del Decreto 0622 de 1977).

El Parque Nacional Natural Old Providence y Mc Bean Lagoon, ocupa un área de Manglar en la isla de Providencia.

Resolución 1265 del 25 de octubre de 1995, del Ministerio del Medio Ambiente. Por el cual se realinderó el Parque Nacional Natural Isla de Gorgona.

Resolución 0186 del 6 de junio de 1996, del Ministerio de Agricultura. Por la cual se determina al valor de establecimiento y mantenimiento que se reconocerá por concepto de Certificado de Incentivo Forestal, CIF para el Caucho (Hevea brasiliensis), se fija el incentivo por árbol, y se actualiza la lista de especies forestales.

En el Art. 4, se ofrece la lista de especies forestales objeto de incendios, y se incluyen Avicennia germinas, Laguncularia racemosa y Rhizophora mangle. 
Acuerdo 0023 Bis del 26 de noviembre de 1996, del Departamento Administrativo del Medio Ambiente de Cartagena DAMARENA. Por el cual se declara una Zona de Reserva Ecológica y Manejo Ambiental.

En el Art.26 se destina la zona de manglar baldía con referencia catastral 01-37-00-053-000 como Zona de Reserva Ecológica y Parque Forestal y Zoológico, en el Art 30, se da al área el nombre de Parque Forestal y Zoológico Cacique Dulio, jefe de la cultura indígena Caribe, y cerca de la desembocadura del Canal del Dique en la Bahía de Cartagena.

Resolución 1425 del 20 de diciembre de 1996, del Ministerio del Medio Ambiente. Por medio del cual se realinderó el área del Parque Nacional Natural los Corales del Rosario y San Bernardo.

Dentro de los límites del Parque, el bioma dominante son los manglares, que están asociados a ciénagas costeras, lagunas internas, islotes o en el propio mar.

Resolución 1426 del 20 de diciembre de 1996, del Ministerio del Medio Ambiente. Por la cual se reserva, alindera y declara el Área de Manejo Especial Los Corales del Archipiélago de San Andrés, Providencia, Santa Catalina y Cayos.

Artículo 1. En desarrollo del [Artículo 308 del Decreto 2811 de 1974], declárese como Área de Manejo Especial para la administración, manejo y protección del ambiente y de los recursos naturales renovables el área del Departamento Archipiélago de San Andrés, Providencia y Santa Catalina, erigido en el [Artículo 309 de la Constitución Nacional].

Artículo 2. El Área de Manejo Especial que se crea mediante esta Resolución se denominará “Área de Manejo Especial Los Corales del Archipiélago de San Andrés, Providencia, Santa Catalina y Cayos" y tiene por objeto:

1. Proteger el ambiente mediante la regulación de las actividades que se realizan dentro del área.

2. Conservar y proteger los valores naturales del área, los bosques higrotropofíticos, manglares, formaciones coralinas, praderas de fanerógamas marinas, los endemismos de la región y fauna existente, que tienen una especial importancia por su fragilidad.

4. Fomentar la investigación aplicada en áreas intervenidas o alteradas, para de este modo ayudar a la sucesión natural, a la recuperación de los recursos naturales, al conocimiento sobre los mismos y a su manejo sostenible por parte de las comunidades.

9. Reglamentar y ordenar la actividad pesquera en la región.

10. Fomentar la implementación de proyectos y tecnologías alternativas para el uso y manejo de los recursos naturales.

12. Desarrollar modelos de manejo integrado y sostenible de los recursos naturales renovables.

Artículo 3. La administración y manejo ambiental del "Área de Manejo Especial Los Corales del Archipiélago de San Andrés, Providencia, Santa Catalina y Cayos" estará a cargo del Ministerio del Medio Ambiente en cuanto a las áreas declaradas o que se puedan declarar como integrantes del Sistema de Parques Nacionales Naturales, y en lo demás a la Corporación para el Desarrollo Sostenible del Archipiélago de San Andrés, Providencia y Santa Catalina, CORALINA para el desarrollo y puesta en práctica de los mecanismos de participación de las comunidades asentadas en el Área de Manejo Especial.

Resolución 0472 del 8 de junio de 1998. Por la cual se re-categoriza y se redelimita el Parque Nacional Natural de la Isla de Salamanca.

Artículo 1. Re-categorizar el Parque Nacional Natural de la Isla de Salamanca en la categoría de Vía Parque. Por lo tanto y para todos los efectos legales el área reservada y delimitada se denominará Vía Parque Isla de Salamanca.

Artículo 2. Ampliar y redelimitar el área protegida por la Vía Parque Isla de Salamanca, ubicada en jurisdicción de los municipios de Sitio Nuevo, Pueblo Viejo y Ciénaga, en una extensión de treinta y cinco mil doscientas (35.200) hectáreas, completando así una superficie total aproximada de cincuenta y seis mil doscientas (56.200) hectáreas.

Resolución 0721 del 31 de julio de 2002, del Ministerio del Medio Ambiente. Por la cual se emite pronunciamiento sobre los estudios y propuestas de zonificación en áreas de manglares presentados por las Corporaciones Autónomas Regionales y de Desarrollo Sostenible y se adoptan otras determinaciones.

Que dentro de las funciones que le corresponden a las Corporaciones Autónomas Regionales, según el artículo 31 de la Ley 99 de 1993 se hallan las de "Ejercer la función de máxima autoridad ambiental en el área de su jurisdicción, de acuerdo 
con las normas de carácter superior y conforme a los criterios y directrices trazadas por el Ministerio del Medio Ambiente" y "Promover y desarrollar la participación comunitaria en actividades y programas de protección ambiental, de desarrollo sostenible y de manejo adecuado de los recursos naturales renovables";

Que la Dirección General de Ecosistemas de este Ministerio, con relación a los estudios presentados por CARSUCRE, CORALINA, CORPAMAG, CRA, CVS, CVC y CARDIQUE, se manifestó a través de concepto técnico remitido mediante el Memorando 2100-3-655 del 19 de diciembre de 2001.

Resolución 0763 de agosto 5 de 2002, del Ministerio del Medio Ambiente. Por la cual se reserva, alindera y declara el Santuario de Fauna y Flora El Corchal "El Mono Hernández"

El SFF El Corchal "El Mono Hernández" (Jorge I. Hernández-Camacho) hace parte de los Municipios de San Onofre (Departamento de Sucre) y Arjona (Departamento de Bolívar), sobre la planicie aluvial del Canal del Dique. El Santuario posee gran importancia a nivel biológico, ya que en su interior se protegen cerca de 1961 hectáreas de bosques de manglar ubicados al $\mathrm{W}$ y al $\mathrm{N}$ del mismo, poblando la línea costera y las zonas aledañas a los márgenes de los caños y las ciénagas. Estos manglares están dominados por las 5 especies de mangle registradas en el Caribe de Colombia, y son importantes a nivel económico para los habitantes asentados en el área de influencia, ya que la función ambiental de este tipo de ecosistema es contribuir con la producción de recursos pesqueros e hidrobiológicos para la región. Igualmente, el área conserva en buen estado las únicas muestras representativas de rodales puros de bosques pantanosos de Corcho en el Caribe colombiano, dominados por la especie Pterocarpus officinalis y que sumados poseen una extensión aproximada de 401 hectáreas ubicados en la parte central sur, en inmediaciones de los Caños Portobelo, Rico y Correa.

\section{- Costas del Océano Pacífico}

Acuerdo 0055 del 10 de diciembre de 1973, del INDERENA. Por el cual se destina un área boscosa de la Zona de Reserva Forestal del Pacífico para otorgar un permiso persistente a la Asociación de Usuarios de Buenaventura.

Se incluyen diferentes áreas de manglar, especialmente en las desembocaduras de los ríos en el Océano Pacífico.
Acuerdo 0030 del 20 de noviembre de 1976, del INDERENA. Por el cual se reglamenta el aprovechamiento forestal de traviesas de ferrocarril con destino a la exportación.

Se incluyen diferentes especies entre las cuales se encuentra el Mangle Nato o Nato Rojo (Mora oleifera), de la cual solo se autoriza la exportación de traviesas $(22.5 \mathrm{~cm}$ de ancho, $3 \mathrm{~m}$ de largo, $17.5 \mathrm{~cm}$ de sección transversal) para vías de ferrocarril, que salgan por los puertos de Océano Pacífico; se aclara que el largo puede ser mayor de $3 \mathrm{~m}$, si el INDERENA lo considera justificable. Posteriormente el INCOMEX expidió la Resolución No. 103 del 17 de octubre de 1978 ratificando estas consideraciones técnicas y al parecer otorgando al Mangle la posición arancelaria 14.05.01.12, con la anotación de que se podrá autorizar la exportación de los productos provenientes de la flora silvestre, previo visto bueno del INDERENA.

Acuerdo 0022 del 2 de mayo de 1977, del INDERENA. Por el cual se reserva, alinda y declara como Parque Nacional Natural un área ubicada en el Departamento de Nariño.

Artículo 1. Con el objeto de conservar la flora, la fauna, las bellezas escénicas naturales, complejos geomorfológicos, manifestaciones históricas o culturales, con fines científicos, educativos, recreativos o estéticos, delimitase y reservase un área de ochenta mil (80.000) hectáreas de superficie aproximada que se denominará Parque Nacional Natural Sanquianga, ubicada dentro de la jurisdicción municipal de Mosquera en el Departamento de Nariño.

Resolución 0161 del 6 de junio de 1977, del Ministerio de Agricultura. Por la cual se aprueba el Acuerdo 0022 del 2 de mayo de 1977, originario de la Junta Directiva del Instituto Nacional de los Recursos Naturales Renovables y del Ambiente INDERENA.

Resolución 0463 del 21 de abril de 1982, del INDERENA. Por medio de la cual se prohíbe el aprovechamiento y comercialización de varas de madera.

En el Artículo 1, se incluye la prohibición para el aprovechamiento de varas en todo el pacífico colombiano, para especies forestales de Mangle, con diámetros menores de $15 \mathrm{~cm}$ de DAP.

Resolución 0141 del 19 de julio de 1984, del Ministerio del Medio Ambiente. Por la cual se aprueba un Acuerdo de la Junta Directiva del Instituto Nacional de los Recursos Naturales Renovables y del Ambiente-INDERENA-

Artículo 1. Aprobar el Acuerdo 0062 expedido por la Junta Directiva del Instituto Nacional de los 
Recursos Naturales Renovables y del Ambiente INDERENA, el 25 de noviembre de 1983, que a la letra dice:

Acuerdo 0062 del 25 de noviembre de 1983, del Ministerio del Medio Ambiente. Por el cual se reserva, alinda y declara como Parque Nacional Natural un área ubicada en el Departamento del Cauca.

Artículo 1. Con el objeto de conservar la flora, la fauna y las bellezas escénicas naturales, complejos geomorfológicos, manifestaciones históricas, culturales, con fines científicos, educativos, recreativos o estéticos, delimitase y reservase un área de cuarenta y nueve mil doscientas (49.200) hectáreas de superficie aproximada, que se denominará PNN Gorgona, ubicado dentro de la jurisdicción municipal del Municipio de Guapi (Departamento del Cauca).

Parágrafo. Constituyen parte integral del PNN Gorgona, todas las islas, cayos y afloraciones recosas que se encuentren dentro de la zona alindada en este artículo.

Acuerdo 0052 del 4 de diciembre de 1986, del Ministerio del Medio Ambiente. Por el cual se reserva, alinda y declara como Parque Nacional Natural Utría, un área ubicada en el Departamento del Chocó.

Artículo 1. Con el objeto de conservar la flora, la fauna, las bellezas escénicas naturales, complejos geomorfológicos, manifestaciones históricas o culturales, con fines científicos, educativos, recreativos o estéticos, delimitase y reservase un área de Cincuenta y cuatro mil trescientas (54.300) hectáreas de superficie aproximada, que se denominará PNN Utría, ubicado dentro de las jurisdicciones municipales de Bahía Solano, Bojay, Alto Baudó y Nuquí, en el Departamento del Chocó.

Acuerdo 0030 del 5 de mayo de 1987. Por el cual se adicionan los Acuerdos números 0044 y 0045 del 20 de octubre de 1986 y el Acuerdo número 0052 del 4 de diciembre de 1986.

Artículo 1. Adicionar los Acuerdos 0044 y 0045 del 20 de octubre de 1986 y el Acuerdo 0052 del 4 de diciembre de 1986 en el Artículo 3o: Al tenor de lo dispuesto por el [Artículo 20 del Decreto 0622 de 1977], las obras de interés publicó, declaradas como tales por elGobierno Nacional, que sea imprescindible realizar en un área del Sistema de Parques Nacionales Naturales, deberán estar precedidas del estudio ecológico y ambiental de que trata el [Artículo $28 \mathrm{del}$ Decreto Ley 2811 de 1974], el cual será evaluado por el INDERENA, entidad que determinará la viabilidad de la obra a través de la Junta Directiva".
Resolución 0190 del 19 de octubre de 1987, del Ministerio de Agricultura. Por la cual se aprueban los Acuerdos 0044 y 0045 del 20 de octubre de 1986, 0052 del 4 de diciembre de 1986 y 0030 del 5 de mayo de 1987, originario de la Junta Directiva del INDERENA y alindero el área del Parque Nacional Natural Utría.

En la Ensenada de Utría, se ubican cuatro sectores que contienen poblaciones de manglares. En el norte de Chunga, Terrón Colorado y la Aguara Norte, así como en el extremo sur la Aguara Sur.

Acuerdo CD-024 del 18 de julio de 1997, de la Corporación Autónoma Regional del Valle del Cauca, CVC. Por el cual se prorroga la veda temporal para el aprovechamiento, movilización y comercialización de productos provenientes del ecosistema manglar en el Departamento del Valle del Cauca.

Artículo 1. Prorrogar la veda establecida en el [Acuerdo CD-18 de agosto 14 de 1995] para el Aprovechamiento, Movilización y Comercialización de las variedades del ecosistema de Manglar (Rhizophora mangle, Avicennia germinans, Laguncularia racemosa, Pelliciera rhizophoreae, Conocapus erecta y Mora megistosperma); por el término de tres años contados a partir del 13 de agosto de 1997, en el todo el Departamento del Valle del Cauca.

Resolución 0037 del 9 de febrero de 1998, de la Corporación Autónoma Regional del Nariño CORPONARIÑO. Por medio de la cual se establece una veda temporal de mangle en el Departamento de Nariño.

El Artículo 1, incluye todas las especies de mangle, incluso el Nato (Mora megistosperma), por un periodo de tres años.

\section{CONCLUSIONES}

La Constitución Política de Colombia de 1991 elevó a norma constitucional la consideración, manejo y conservación de los recursos naturales y el medio ambiente, a través de los siguientes principios fundamentales:

\section{Derecho a un ambiente sano}

En su Artículo 79, la Constitución Nacional $(\mathrm{CN})$ consagra que: "Todas las personas tienen derecho a gozar de un ambiente sano. La Ley garantizará la participación de la comunidad en las decisiones que puedan afectarlo. Es deber del Estado proteger la diversidad e integridad del ambiente, conservar las áreas de especial importancia ecológica y fomentar la educación para el logro de estos fines". Esta norma constitucional 
puede interpretarse de manera solidaria con el principio fundamental del derecho a la vida, ya que éste sólo se podría garantizar bajo condiciones en las cuales la vida pueda disfrutarse con calidad.

El medio ambiente como patrimonio común

La CNC de Colombia incorpora este principio al imponer al Estado y a las personas la obligación de proteger las riquezas culturales y naturales (Art. 8), así como el deber de las personas y del ciudadano de proteger los recursos naturales y de velar por la conservación del ambiente (Art. 95). En desarrollo de este principio, en el Art. 58 consagra que: "la propiedad es una función social que implica obligaciones $\mathrm{y}$, como tal, le es inherente una función ecológica"; continúa su desarrollo al determinar en el Art. 63 que: "Los bienes de uso público, los parques naturales, las tierras comunales de grupos étnicos, las tierras de resguardo, el patrimonio arqueológico de la Nación y los demás bienes que determine la Ley, son inalienables, imprescriptibles e inembargables".

\section{Desarrollo Sostenible}

Definido como el desarrollo que conduce al crecimiento económico, a la elevación de la calidad de vida y al bienestar social, sin agotar la base de los recursos naturales renovables en que se sustenta, ni deteriorar el medio ambiente o el derecho de las generaciones futuras a utilizarlo para la satisfacción de sus propias necesidades, la $\mathrm{CN}$ en desarrollo de este principio, consagró en su Art. 80o. que: "El Estado planificará el manejo y aprovechamiento de los recursos naturales para garantizar su desarrollo sostenible, su conservación o sustitución. Además, deberá prevenir y controlar los factores de deterioro ambiental, imponer las sanciones legales y exigir la reparación de los daños causados. Así mismo, cooperará con otras naciones en la protección de los ecosistemas situados en zonas fronterizas". Lo anterior implica asegurar que la satisfacción de las necesidades actuales se realice de una manera tal que no comprometa la capacidad y el derecho de las futuras generaciones para satisfacer las propias.

\section{Normatividad Temática}

Donde se tienen en cuenta las principales normas constitucionales relacionadas con el manejo y conservación de los recursos naturales y el medio ambiente, de acuerdo con las diferentes temáticas involucradas en el desarrollo de las actividades de la zona costera y los manglares

\section{Jurisprudencia}

Es el avance más significativo en materia constitucional en la protección de los derechos al Medio Ambiente, donde la Corte Constitucional a efectuado el estudio y las consideraciones de hecho y de derecho de las afectaciones a ecosistemas de manglar y sus áreas de influencia en Colombia, donde sobresalen 5 sentencias en particular:

1. Sentencia C-649 del 3 de diciembre de 1997 (sobre Impactos Ambientales) Ponente el Magistrado Antonio Barrera Carbonell.

Sentencia de constitucionalidad sobre la Ley 99 de 1993 art, 5 n¹7 y 18 parciales, art. 11 parágrafo 1. Funciones del Ministerio del Medio Ambiente. Exequible e inexequible.

2. Sentencia C-339 del 7 de mayo de 2002 (sobre el Derecho al Medio Ambiente Sano) Ponente el Magistrado Jaime Araujo Rentería.

Sentencia de constitucionalidad sobre la Ley 685 de 2001. Arts. 3 (p.), 4, 18 (p.), 34, 35 (p.), literales. A) y c) y 36 (р.). Código de Minas. Regulación completa y general. Aplicación preferente. Personas naturales y jurídicas extranjeras. Zonas excluibles de la minería, de minería restringida, de interés arqueológico, histórico o cultural. Efectos de la exclusión o restricción. Normas subordinadas. Medio ambiente sano. Construcción conjunta del Estado y ciudadanos. Conservación de la biodiversidad. Impuesto ambiental. Desarrollo sostenible. Impacto ambiental. Principio de precaución. Exequible e inexequible.

3. Sentencia T-294 del 25 de marzo de 2004 (sobre Caso en La Boquilla) Ponente el Magistrado Manuel José Cepeda Espinosa.

Sentencia de Tutela - Derecho al debido proceso. Indebida notificación en proceso de pertenencia bien inmueble de uso público. Prescripción adquisitiva. Inaplicación normativa. Acceso a particulares. Daño ambiental en ciénaga. Legitimación por activa. Tutela contra providencia judicial. Concedida.

4. Sentencia C-189 del 15 de marzo de 2006 (sobre Parques Nacionales Naturales) Ponente el Magistrado Rodrigo Escobar-Gil.

Sentencia de Tutela - Ley $2^{\text {a }}$ de 1959 Articulo 13 (parcial). Sobre economía forestal de la Nación y 
conservación de recursos naturales renovables. Prohibición de ventas de tierras en parques nacionales naturales. El demandante considera que la disposición acusada vulnera los Artículos 2, 5, 8, 13, 58, 63, 79 y 102 de la Constitución Política. Del derecho a la propiedad privada y su función ecológica en el estado social de derecho. Características del derecho de propiedad. Núcleo esencial del derecho a la propiedad privada. Es compatible con el núcleo esencial del derecho a la propiedad privada que el legislador establezca prohibiciones temporales o absolutas de enajenación sobre algunos bienes, siempre y cuando se acredite que las mismas, además de preservar un interés superior que goce de prioridad en aras de salvaguardar los fines del estado social de derecho, mantienen a salvo el ejercicio de los atributos de goce, uso y explotación, los cuales no sólo le confieren a su titular la posibilidad de obtener utilidad económica, sino también le permiten legitimar la existencia de un interés privado en la propiedad. Concluye esta corporación, que al disponer la norma acusada la prohibición de ventas de tierras, lo que establece es una restricción para llevar a cabo la enajenación a través del instituto de la compraventa, de todo tipo de bienes que se encuentren ubicados en las zonas correspondientes al sistema de parques nacionales naturales, en la medida en que la ley no distingue la clase de propiedad frente a la cual procede dicha prohibición. Exequible

5. Sentencia T-745 del 14 de septiembre de 2010 (sobre Caso en Isla de Barú) Ponente el Magistrado Humberto Antonio Sierra Porto.

Sentencia de Tutela - Derecho a la consulta previa de las comunidades afro-colombianas. Desconocimiento por obras que constituyen el proyecto construcción y mejoramiento de la vía transversal Barú. Legitimación por activa en tutela. Procedencia para proteger derechos reconocidos a grupos étnicos minoritarios. Derecho a la consulta previa de las comunidades étnicamente minoritarias-protección constitucional/derecho a la consulta previa de comunidades étnicamente minoritarias. Análisis sobre sustento constitucional y legal. Derecho a la consulta previa de comunidades afro-colombianas. Vulneración por construcción de carretera en el espacio que material y culturalmente un grupo de afro-colombianos tiene como propio.

\section{REFERENCIAS BIBLIOGRÁFICAS}

Álvarez-León, R. Bibliografía sobre los ecosistemas de manglar en Colombia. (Cuarta revisión), p. 1-112 in Álvarez-León, R. \& Páez-Parra, F.E. (eds.) Proy. PD 171 / 91 Rev. (F) Fase 1 Conservación y Manejo para el Uso Múltiple y el Desarrollo de los Manglares en Colombia, MMA / OIMT. Santa Fe de Bogotá D.C. (Colombia). Inf. Técnico, 9: 112 p. +5 anexos, 2 mapas, 1997.

Álvarez-León, R. Los manglares de Colombia y la recuperación de sus áreas degradadas: revisión bibliográfica y nuevas experiencias. Rev. Madera y Bosques, v. 9, n.1, p. 3-25, 2003.

Araujo-Rentería, J. Sentencia C-339 del 7 de mayo de 2002. Corte Constitucional. Bogotá D.C. (Colombia), 39 p., 2002.

Barrera-Carbonell, A. Sentencia C-649 del 3 de diciembre de 1997. Corte Constitucional. Bogotá D.C. (Colombia), 26 p., 1997.

Cepeda-Espinosa, M.J. Sentencia T-294 del 25 de marzo de 2004. Corte Constitucional. Bogotá D.C. (Colombia), 36 p., 2004.

Del Valle-Arango, J.I. Los bosques de guandal del delta del río Patía (Colombia). Rev. Acad. Colomb. Cienc., v. 20, n.78, p. 475-489, 1996.

Escobar-Gil, R. Sentencia C-189 del 15 de marzo de 2006. Corte Constitucional. Bogotá D.C. (Colombia), 31 p., 2006.

Gaviria-Flórez, J.E. \& González-Palacio, M.P. Incidencia de algunos factores ambientales en la distribución del bosque de manglar en la isla Grajales, delta del río San Juan, Pacífico colombiano. Tesis de Ingeniería Forestal. Facultad de Ciencias Agropecuarias. Univ. Nal. de Colombia-Sede Medellín, 1998.

Guevara-Mancera, O.A. Manual para la restauración de los bosques de manglar en áreas degradadas del Pacífico colombiano. p. 1-16 in Álvarez-León, R. \& Páez-Parra, F.E. (eds.) Proyecto PD 171/91 Rev. 2 Fase II (Etapa 1) Conservación y Manejo para el Uso Múltiple y el Desarrollo de los Manglares en Colombia, MMA / ACOFORE / OIMT, Santa Fe de Bogotá D. C. (Colombia), 1998.

Guevara-Mancera, O.A., Sánchez-Páez, H.; MurciaOrjuela, G.O.; Bravo-Pazmiño, H.E.; Pinto-Nolla, F. \& Álvarez-León, R. Conservación y uso sostenible de los manglares del Pacífico colombiano, in: Sánchez-Páez, H., Guevara-Mancera, O.A. \& Alvarez-León, R. (eds.) Proy. PD 171/91 Rev. 2 Fase II (Etapa I) 
Conservación y Manejo para el Uso Múltiple y el Desarrollo de los Manglares de Colombia, MINAMBIENTE / ACOFORE / OIMT. Santa Fe de Bogotá D.C. (Colombia), 178 p., 1998.

Neyra-Román, M. Investigación y desarrollo forestal: Colombia. Proy. Silvicultura INDERENA / PNUD / FAO / CONIF- Col / 74 / 005. Roma (Italia). Doc. de Trabajo, 222 p., 1981.

Rodríguez-Cruz, H. Restauración de las áreas de manglar en el Caribe continental de Colombia, p. 1- 38 in: Âlvarez-León, R. \& Páez-Parra, F.E. (eds.). Proy. "Conservación y Manejo para el Uso Múltiple y el Desarrollo de los Manglares de Colombia", PD 171/91 Rev. 2(F). Santa Fe de Bogotá D.C. (Colombia). Inf. Técnico, 20, 1998.

Sánchez-Páez, H. \& Ulloa-Delgado, G.A. Experiencias de restauración en el Proyecto Manglares de Colombia, $\mathrm{p}$. 219-258 in: Ponce de León, E. (ed.) Mem. Sem. Sem. Nal. de Restauración Ecológica y Reforestación, FAAE / FFEC / FESCOL / FNA / GTZ, dic. 2 y 3 de 1999. Santa Fe de Bogotá D.C. (Colombia), 2000.

Sánchez-Páez, H.; Álvarez-León, R.; GuevaraMancera, O.A. \& Ulloa-Delgado, G.A. Lineamientos estratégicos para la conservación y uso sostenible de los manglares de Colombia. Proy. PD 171/91 Rev. 2 (F) Fase II (Etapa II). Conservación y Manejo para el Uso Múltiple y el Desarrollo de los Manglares de Colombia, MINAMBIENTE / OIMT. Santa Fe de Bogotá D.C. (Colombia), 81 p., 2000.

Sánchez-Páez, H., R. Álvarez-León, F. Pinto-Nolla, A.S. Sánchez-Alférez, J.C. Pino-Renjifo, I. GarcíaHansen \& M.T. Acosta-Peñaloza. Diagnóstico y Zonificación Preliminar de los manglares del Caribe de Colombia. in Sánchez-Páez, H. \& R. Álvarez-León (eds.) Proy. PD 171/91 Rev. 2 (F) Fase I. Conservación y Manejo para el Uso Múltiple y el Desarrollo de los Manglares de Colombia, MINAMBIENTE / OIMT. Santa Fe de Bogotá D.C. (Colombia), 511 p., 1997a.

Sánchez-Páez, H.; Álvarez-León, R.; GuevaraMancera, O.A.; Zamora-Guzmán, A.; RodríguezCruz, H. \& Bravo-Pazmiño, H.E. Diagnóstico y Zonificación Preliminar de los manglares del Pacífico de Colombia. In Sánchez-Páez, H. \& R. Álvarez-León (eds.) Proy. PD 171/91 Rev. 2 (F) Fase I. Conservación y Manejo para el Uso Múltiple y el Desarrollo de los Manglares de Colombia, MINAMBIENTE / OIMT. Santa Fe de Bogotá D. C. (Colombia), 343 p., 1997b.

Sánchez-Páez, H.; Ulloa-Delgado, G.A.; ÁlvarezLeón, R.; Gil-Torres, W.O.; Sánchez-Alférez, A.S.; Guevara-Mancera, O.A.; Callejas, L.P. \& Páez-Parra,
F.E. Hacia la recuperación de los manglares del Caribe de Colombia. in Sánchez-Páez, H., Ulloa-Delgado, G.A. \& Álvarez-León, R. (eds.) Proy. PD 171/91 Rev. 2 (F) Fase II (Etapa II). Conservación y Manejo para el Uso Múltiple y el Desarrollo de los Manglares de Colombia, MINAMBIENTE / OIMT. Santa Fe de Bogotá D. C. (Colombia), 294 p., 2000.

Sierra-Porto, H.A. Sentencia T-745 del 14 de septiembre de 2010. Corte Constitucional. Bogotá D. C. Colombia, 62 p., 2010.

Silva, L.J. La investigación silvicultural en el bosque húmedo tropical en Colombia, p. 36-53 in Solano, R. (ed.) Mem. Reu. Nal. de Silvicultura: Impacto de la Investigación Silvicultural Tropical en el Desarrollo Económico Forestal Colombiano, Bogotá D.E. (Colombia), abril 7-10. CONIF-Ser. Doc., 318 p., 1987.

Ulloa-Delgado, G.A.; Gil-Torres, W.O.; Pino-Rengifo, J.C. \& Rodríguez-Cruz, H. Manual sobre técnicas de vivero y restauración de áreas de manglar del Caribe colombiano. in Álvarez-León, R. \& Páez-Parra, F.E. (eds.) Proyecto PD 171/91 Rev. 2 Fase II (Etapa I) Conservación y Manejo para el Uso Múltiple y el Desarrollo de los Manglares en Colombia, MMA / ACOFORE / OIMT, Santa Fe de Bogotá D. C. (Colombia), 24 p., 1998a.

Ulloa-Delgado, G.A., H. Sánchez-Páez, W.O. GilTorres, J.C. Pino-Rengifo, H. Rodríguez-Cruz \& Álvarez-León, R. Conservación y uso sostenible de los manglares del Caribe colombiano. in Ulloa-Delgado, G. A.; Sánchez-Páez, H. \& Álvarez-León, R. (eds.). Proyecto PD 171/91 Rev. 2 Fase II (Etapa I) Conservación y Manejo para el Uso Múltiple y el Desarrollo de los Manglares en Colombia, MMA / ACOFORE / OIMT, Santa Fe de Bogotá D. C. (Colombia), 224 p., 1998b.

Zambrano-Escamilla, C.H. \& Rubiano-Rubiano, D.J. Memoria de los mapas de los bosques de manglar del Pacífico colombiano: 1969, 1996 y multitemporal. p. 1-41 in Álvarez-León, R. \& Páez-Parra, F.E. (eds.) Proyecto PD 171/91 Rev. 2 (F) Fase I. Conservación y Manejo para el Uso Múltiple y el Desarrollo de los Manglares en Colombia, MINAMBIENTE / OIMT. Santa Fe de Bogotá D. C.(Colombia). Inf. Técnico, 8, 1996.

Zambrano-Escamilla, C.H. \& Rubiano-Rubiano, D.J. Memoria de los mapas de los bosques de manglar del Caribe colombiano: 1996. p. 1-22. in Álvarez-León, R. \& Páez-Parra, F.E. Proyecto PD 171/91 Rev. 2 (F) Fase I. Conservación y Manejo para el Uso Múltiple y el Desarrollo de los Manglares en Colombia, MINAMBIENTE / OIMT. Santa Fe de Bogotá D. C.(Colombia). Inf. Técnico, 11, 1997. 
